\title{
The service quality-satisfaction link revisited: exploring asymmetries and dynamics
}

\author{
Tomas Falk • Maik Hammerschmidt • \\ Jeroen J. L. Schepers
}

Received: 5 June 2008 / Accepted: 25 May 2009 / Published online: 30 July 2009

(C) The Author(s) 2009. This article is published with open access at Springerlink.com

\begin{abstract}
This study provides deeper insight in the link between service quality and customer satisfaction. The traditional assumption of a linear relationship is challenged by exploring asymmetries and dynamics. The simultaneous influence of service quality and customer experience on satisfaction is examined by means of nonlinear structural equation modeling. Results show that functional-utilitarian quality attributes (availability, efficiency, fulfillment, and privacy) lose their capability to delight customers as the customer relationship matures. In contrast, hedonic quality attributes (design, enjoyment, and image) only exhibit an increasing effect on satisfaction for more experienced customers. These insights are vital for service managers as they help to improve the efficiency of quality investments.
\end{abstract}

Keywords Customer satisfaction · Service quality

Asymmetric effects · Customer experience .

Nonlinear structural equation modeling

\section{Introduction}

While researchers generally agree that favorable service quality perceptions lead to improved satisfaction, in

T. Falk $\cdot$ M. Hammerschmidt $(\bowtie)$

University of Mannheim,

L 5, 1, 68131 Mannheim, Germany

e-mail: maik.hammerschmidt@bwl.uni-mannheim.de

T. Falk

e-mail: tomas.falk@bwl.uni-mannheim.de

\section{J. J. L. Schepers}

Eindhoven University of Technology,

Den Dolech 2, Pav. L 07, Postbus 513, 5600 MB Eindhoven, Netherlands

e-mail: j.j.l.schepers@tue.nl practice many quality initiatives fail to deliver anticipated results (Anderson and Mittal 2000). Such disappointing outcomes have undermined service marketing's credibility and periled quality management as a distinct capability of firms (Rust and Chung 2006). With service quality being the fundament of the satisfaction-profit chain, firms have to solidify their understanding of this construct and its consequences. This is a necessary first step for assuring profitable outcomes of service efforts. Therefore, the call for developing a deeper comprehension of service quality's influence on customer satisfaction represents a hotbed for both business practitioners and marketing scholars (Anderson 2006).

Assuming a linear relationship between service quality and satisfaction, many service providers continuously add new features to improve their offerings (Thompson et al. 2005). However, recent findings suggest that this relationship may be nonlinear and thus quality improvements may have an asymmetric effect on satisfaction. That is, the negative effect of a one-unit decrease of service quality on overall satisfaction could be greater than the positive effect of a corresponding unit of increase or vice versa (Anderson and Mittal 2000; Mittal et al. 1998). In addition, service managers have to be aware that customer relationships unfold over time (Bolton and Lemon 1999). Quality attributes that impact the satisfaction of newly acquired customers may have little influence on the satisfaction of long-term clients. Understanding such dynamics in customer judgments is an important prerequisite for successfully addressing customer needs across the stages of a relationship (Rust et al. 1999). Research even calls for developing separate strategies for newly acquired and more established customers (Mittal and Katrichis 2000). Surprisingly, while the quality-satisfaction relationship is both nonlinear and dynamic, these issues have been studied in isolation. Yet, as 
also called for by Slotegraaf and Inman (2004), an integrative perspective is needed in order to prevent serious resource misallocation. Taking an integrated view is necessary as service providers improving their service quality may not do a good job if they continue to invest in quality factors that show diminishing returns to quality (i.e., negative asymmetries) for long-term customers. Hence, it is important to identify attributes that augment satisfaction at an increasing rate as a customer relationship progresses (i.e., that exhibit positive asymmetries).

This knowledge is pivotal for e-service providers given their recent experiences that not all investments in website features are equally reflected in customer behavior beneficial to the firm (Thompson et al. 2005). On the Internet, both effort and funds are invested in a wide array of customization, privacy and community-related features, but the key issue is whether these website attributes really continuously improve customer evaluations. For instance, Cheung and Lee (2005) identify positive and negative asymmetric effects of website attribute performance on customer satisfaction. Yet, they find some effects opposite to their hypothesized direction and in general report inconclusive results. These authors therefore call to investigate the conditions under which asymmetries have a positive or negative valence. Technology adoption literature suggests that time may be such a condition, as customer technology perceptions vary with experience (Venkatesh et al. 2003). Considering the active role and broad integration of customers as part-time employees in the production of eservices (Rust and Kannan 2002), such experience-related effects should occur especially for services on the Internet. Therefore, as a first contribution this paper takes an integrative perspective in studying asymmetries and dynamics in an e-service context. More precisely, we investigate whether improvements of service quality attributes enhance satisfaction at increasing or decreasing rates as a customer relationship progresses.

The type of service quality attribute reflects another condition that might influence the valence of asymmetries. Recent studies stress the importance of hedonic service attributes like enjoyment as drivers of satisfaction in both offline and online environments (Chitturi et al. 2008; Van Dolen et al. 2007). Indeed, with the increasing convergence of functional-utilitarian service attributes such as fastloading webpages, the impact of hedonic elements could be significant (Dhar and Wertenbroch 2000). Therefore, as a second contribution, we compare the impact of functional-utilitarian quality attributes to the impact of hedonic quality attributes on customer satisfaction. More specifically, we expect functional-utilitarian attributes to evolve in a way that their ability to trigger disproportionally high levels of customer satisfaction (i.e., customer delight) fades over time, while hedonic factors reveal their delight-creating potential only in later stages of a relationship.

Third, previous studies considering asymmetries have applied a dummy-variable regression methodology (Cheung and Lee 2005; Matzler et al. 2004). Here, dummy variables are created based on median or quartile splits of the data. Yet, this methodological approach focuses on the extremes rather then the entire spectrum of possible values causing a loss of information concerning the independent variables. As a response to this problem, we take a more robust approach by applying nonlinear structural equation modeling. More specifically, we test for latent quadratic effects of functional-utilitarian and hedonic e-service quality on customer satisfaction (Marsh et al. 2004).

We structure this paper as follows. We first establish our conceptual framework and formulate our hypotheses by deriving important insights from relevant theories and literature. We then examine the nature of the service quality-satisfaction relationship based on quantitative data for two electronic service settings. We conclude with theoretical and practical implications.

\section{Conceptual framework}

Symmetric versus asymmetric effects of quality

Traditionally, research on customer satisfaction has used the expectancy-disconfirmation paradigm (Oliver et al. 1997), where satisfaction is the discrepancy between expectations and perceived quality (i.e., performance). Expectations act as a reference point. Performance outcomes poorer than expected are rated below the reference point and lead to dissatisfaction (negative disconfirmation). Performance outcomes can also meet the reference point (confirmation) or even exceed it (positive disconfirmation), both leading to satisfaction. A shortcoming of the disconfirmation paradigm is that while exceeding or falling below a base point will affect the satisfaction judgment in different directions, the effect sizes of these performance deviations are assumed to be identical. As a consequence, symmetric effects of quality on customer satisfaction would have to be expected. The idea of symmetric effects is challenged by the model of Kano et al. (1984) identifying three types of quality attributes: (1) basic attributes, (2) performance attributes, and (3) excitement attributes.

The presence of attributes falling in the first category has only a minor satisfaction enhancing impact, but their absence or a poor performance in these areas exhibits a strong negative influence on customer satisfaction. These attributes can be regarded as having a negative asymmetry (Anderson and Mittal 2000). That is, a one-unit decrease in the level of quality has a larger influence on satisfaction 
compared to a one-unit increase for the same attribute. The second category depicts the traditional view of attributes exhibiting symmetric effects on satisfaction: A one-unit decrease in attribute performance has an equivalent impact on satisfaction as a one-unit increase. Third, excitement attributes are not explicitly articulated by the customer and can result in high levels of customer satisfaction. Yet, their absence does not lead to dissatisfaction. They can therefore be portrayed as exhibiting a positive asymmetry, so that a one-unit increase in quality has a larger influence on satisfaction compared to a one-unit decrease in quality for the same attribute.

Theoretical underpinnings of static asymmetries

The theoretical logic for the existence of negative asymmetries lies in prospect theory which suggests that people judge new options with a degree of reference dependence and loss aversion (Kahneman and Tversky 1979). Gains or losses result from a comparison to a reference point; outcomes above this point are regarded as gains, outcomes below this point are treated as losses. Loss aversion means that a one-unit loss is weighted more than an equal amount of gain. With satisfaction judgments being reference dependent too (Homburg et al. 2005), prospect theory proposes that a one-unit decrease in attribute performance has a larger impact on overall satisfaction than an equal amount of performance increase in the same attribute.

Positive asymmetries on the other hand, find their roots in customer delight theory (Oliver et al. 1997). Customer delight is "a profoundly positive emotional state generally resulting from having one's expectations exceeded to a surprising degree" (Rust and Oliver 2000, p. 86). Factors are delight-creating if no generally accepted standard of performance exists. They have no downside and an unlimited upside. Previous studies have applied these underpinnings to the evaluation of asymmetric effects in the relationship between service quality and customer satisfaction in offline (Mittal et al. 1998) as well as online contexts (Cheung and Lee 2005; Zhang and Von Dran 2001). Nevertheless, these studies examine asymmetries only from a static point of view. The theories underlying static asymmetries should be expanded to make predictions on how asymmetries evolve over time. In the following section, we develop an integrative framework on the dynamics of asymmetries.

Theoretical underpinnings of dynamic asymmetries

The reference point customers use to assess satisfaction is primarily shaped by prior usage of the service (Parasuraman et al. 1991). Hence, quality expectations are influenced by experience and therefore they are likely to change over time. Empirically, Mittal et al. (1999) and Slotegraaf and Inman (2004) provide evidence that product attribute weights for forming customer satisfaction change over time for automotive customers. Mittal et al. (2001) show that for financial and educational services, different service features contribute differentially to dynamic consumers' consumption preferences. Anderson et al. (2008) find that in the airline industry, experts place more emphasis on physical amenities associated with air travel compared to core service performance. ${ }^{1}$ Finally, Dagger and Sweeney (2007) show that for healthcare services, tangible elements of a service are more important to inexperienced customers whereas provider expertise and professionalism are more important to experienced users. Yet, the described dynamics concern linear quality-satisfaction relationships and thus symmetric effects, while we examine how asymmetries evolve over the relationship cycle.

As discussed earlier, the basis for a positive asymmetry lies in customer delight attributes. However, with increasing knowledge on how a service provider performs, the element of surprise fades. Consequently, service attributes formerly recognized as new, interesting, and challenging, lose their ability to trigger customer delight. This is accompanied by rising expectations, because expectations are known to track performance evaluations (Rust and Oliver 2000). As the customer cognitively develops minimum standards with regard to the attribute's performance, the attribute will no longer display an unlimited upside. Negative effects on satisfaction will emerge if the attribute displays low quality levels. Therefore, the initial positive asymmetry has converted into a symmetric effect that mirrors a performance attribute in the Kano model. After this institutionalization, an attribute can spread to become a market standard by means of word-of-mouth and vicarious experience (File et al. 1994), but also by technological advances. For example, in the late nineties, Internet service providers (ISPs) could gain competitive advantage by offering high connection speeds. Yet, due to the fierce competition among ISPs, high speed Internet has rapidly become a market standard. Now, barring some exceptions, ${ }^{2}$ ISPs offering low speed Internet like dial-up connections no longer exist. Hence, after the delight element has faded and symmetric effects are observed, the attribute further develops into a negative asymmetry: Its presence adds little to overall customer satisfaction, but when absent, substantial dissatisfaction arises.

\footnotetext{
${ }^{1}$ We thank an anonymous reviewer for this suggestion.

${ }^{2}$ E.g., NetZero.com occupies a niche position by offering US-wide dial-up connections to occasional Internet users. However, recognizing the current market standards, fast DSL connections are also on offer. We thank an anonymous reviewer for pointing us to this example.
} 
In sum, over the course of time, customer delight principles would predict that the effects of quality change their valence from a positive asymmetry to a negative asymmetry. This is consistent with empirical insights on both product-related and service-related attributes (NilssonWitell and Fundin 2005). However, the "wear-out process" suggested by delight theory might not hold for all types of quality attributes. In line with this, customer satisfaction formation has shown to be primarily based on cognition in the early stages of a customer relationship. In contrast, affect dominates customer satisfaction judgments as clients build a stable relationship towards a provider (Johnson et al. 2006). Accordingly, we propose that asymmetries evolve in different patterns, depending on the subset of quality attributes considered.

Two subsets of attributes: functional-utilitarian and hedonic

Consistent with theoretical insights from diverse disciplines, we make the distinction between two subsets of quality attributes in our e-services context: functionalutilitarian and hedonic service quality attributes. Voss et al. (2003, p. 310, emphasis added) state that "investigation of hedonic and utilitarian components has been suggested in such diverse disciplines as sociology, psychology, and economics." In marketing, a series of articles report similar observations (Dhar and Wertenbroch 2000; Okada 2005). These studies show that the conceptual distinction between a functional-utilitarian and a hedonic attribute subset is essential as both subsets reflect different consumption needs. As such, functional-utilitarian attributes are thought to provide "instrumental and practical benefits" whereas hedonic components provide "aesthetic, experiental, and enjoyment-related benefits" (Chitturi et al. 2008, p. 49).

In order to investigate how the quality effects for both types of attributes evolve, we draw on Maslow's hierarchy of needs framework which states that most basic human needs must be satisfied before higher-level human needs are pursued (Maslow 1954). Translated to an e-services context, functional-utilitarian attributes are more fundamental than hedonic attributes (Valacich et al. 2007). Since inexperienced customers are earlier in the consumption life cycle, they focus more on satisfying fundamental, functional needs. In contrast, experts take the fulfillments of such needs for granted and are more concerned with higher level, hedonic needs. Thus, we suggest a sequential importance of both subsets in a way that a website first has to satisfy the needs of structural firmness (e.g., response time, security) and functional convenience (e.g., ease of use), before hedonic elements are considered (e.g., appealing layout and design).

Previous work seems to support the proposed sequential patterns. In a more general product setting, Chitturi et al.
(2008) show that consumers attach greater weight to hedonic dimensions only after a necessary level of functionality is obtained. With respect to e-services, Childers et al. (2001) find that enjoying aspects of the service encounter ("shopping as fun") are less important for firsttime customers of online shopping than for experienced ones. Moreover, recent studies have identified instrumental motives as the primary determinants for initially choosing an online service channel as they fulfill economic needs for adopting e-services (Parasuraman et al. 2005; Valacich et al. 2007). In view of this, we suggest that individuals first target their cognitive efforts towards functional-utilitarian attributes and only later they divert their attention to the consideration of hedonic elements.

In sum, we expect that functional-utilitarian and hedonic service quality attributes display a different potential to exhibit positive asymmetries (i.e., to create customer delight) across the customer relationship cycle. On the one hand, functional-utilitarian attributes evolve in a way that their ability to exhibit positive asymmetries fades over time. In other words, the likelihood of developing negative asymmetries increases as the relationship matures. On the other hand, hedonic factors reveal their ability to exhibit positive asymmetries only for more experienced users. In other words, the likelihood of developing positive asymmetries increases. Hence, we hypothesize:

Hypothesis 1. As consumers become more experienced, functional-utilitarian e-service quality attributes have a greater potential to exhibit negative asymmetric effects on satisfaction.

Hypothesis 2. As consumers become more experienced, hedonic e-service quality attributes have a greater potential to exhibit positive asymmetric effects on satisfaction.

\section{Research and study design}

\section{Research setting}

In order to improve the generalizability of our findings, we collected data in two e-service settings. First, a German market research institute distributed a questionnaire to randomly selected members of its database. Following the procedure suggested by Parasuraman et al. (2005), participants were asked to recall a recently used online shop and refer to that experience regarding their answers. Among the online shops most commonly referred to were typical Internet retailers such as Amazon.com (30\%) and Bol.com (14\%). These shops offer a multitude of products including books, electronics, household appliances and clothing. Second, users of one of the largest Internet portal sites in 
Germany were targeted in close cooperation with the respective provider. An online questionnaire was presented to randomly selected users of the price and product comparison function of the respective portal. Portal visitors could participate in the survey by clicking on a flash banner. While we make a conceptual distinction between functional and hedonic elements of an e-service in our paper, we do not treat them as mutually exclusive. Hence, both services considered in our study are bundles of hedonic and functional characteristics.

Since the data for this study were collected from customers only, we tried to minimize common method bias a priori by evaluating response styles (Weijters et al. 2008). We integrated two pairs of reversed items: "I knew exactly what I would buy beforehand" / "I decided upon what to buy while I was shopping" (online shop), and "I knew exactly what my product of interest would cost" / "I learned about the price of my product of interest while I was comparing products" (Internet portal). This allowed us to identify acquiescent respondents (Weijters et al. 2008). Specifically, 15 respondents scored high on both statements in the online shop sample and 18 in the Internet portal sample. These respondents were deemed to respond in an inconsistent and acquiescent way and were not included in the analyses. Resulting from this procedure, we obtained a final sample size of 456 online shoppers and 558 portal users. The characteristics of respondents are reported in Table 1.

\section{Measurement}

The assessment of the functional-utilitarian attributes of eservice quality was conducted following the E-S-QUAL operationalization put forward by Parasuraman et al. (2005). They distinguish four dimensions of e-service quality. System availability denotes the correct technical functioning of the website and is tapped by 3 items. Efficiency denotes the ease and speed of accessing and using the website, and is measured with 3 items. Fulfillment is defined as the extent to which the website's promises about order delivery and item availability are fulfilled. However, respondents were only able to order items in the online shop, not on the Internet portal. As the information presented should be accurate and complete, fulfillment indicates whether the information presented here was perceived to be accurate and helpful for online shopping activities. Fulfillment is assessed using 3 items. These items were tailored to the specific context of the online shop and Internet portal respectively. Finally, privacy reflects the degree to which the website is safe and protects customer information, and is measured with 3 items.

To decide on attributes for capturing the hedonic aspects of e-service quality, we studied existing scales. Wolfinbarger
Table 1 Sample characteristics

\begin{tabular}{lcc}
\hline Variable & $\begin{array}{l}\text { Sample 1 } \\
\text { Online shoppers } \\
n=456\end{array}$ & $\begin{array}{l}\text { Sample 2 } \\
\text { Internet portal users } \\
n=558\end{array}$ \\
\hline Age (years) & 34.6 & 35.0 \\
Mean & 12.6 & 13.6 \\
Standard deviation & & \\
Gender (percentage) & 45.0 & 52.0 \\
Female & 55.0 & 48.0 \\
Male & 47.0 & \\
Net household income (percentage) & 47.8 \\
Less than 25.000 Euros & 32.2 & 34.7 \\
25.000-49.999 Euros & 14.3 & 11.9 \\
50.000-75.000 Euros & 6.5 & 5.6 \\
More than 75.000 Euros & & \\
Customer experience (percentage) & 6.2 \\
Less than 6 months & 5.7 & 13.9 \\
6 months to 2 years & 15.6 & 25.1 \\
2-3 years & 28.0 & 15.8 \\
3-4 years & 14.1 & 39.0 \\
More than 4 years & 36.6 & \\
\hline
\end{tabular}

and Gilly (2003), Parasuraman et al. (2005), and Bauer et al. (2006) all point to the importance of website design denoting the visual appeal of the virtual interface. We therefore consider this hedonic factor and measure it with 3 items, adapted from Wolfinbarger and Gilly (2003). In addition, in affecting individual's attitudes towards technology, literature has repeatedly stressed the importance of enjoyment. This dimension captures the entertaining aspect of using the Internet as a service channel and is assessed with 3 items (Childers et al. 2001). Apart from that, studies emphasize the role of image, reflecting the degree to which the use of an innovation is perceived to enhance one's status in the social system (Venkatesh and Davis 2000). Image was measured with 3 items derived from Venkatesh and Davis (2000). Overall customer satisfaction was assessed using 3 items suggested by Szymanski and Hise (2000) and Hennig-Thurau et al. (2002). Apart from items adapted from Szymanski and Hise (2000) which were measured based on two semantic differentials (very dissatisfied-very satisfied and very displeased-very pleased), participants indicated their (dis)agreement with a statement using a 7point Likert scale that ranged from strongly disagree to strongly agree. Finally, customer experience was surveyed by asking about the time period the particular online shop or Internet portal has been used. A complete list of all items and their psychometric properties appears in the Appendix.

Our philosophy for capturing both functional-utilitarian and hedonic aspects of e-service quality is based on the 
item-parceling approach that has been suggested as an appropriate way to reduce the complexity of constructs measured through a large number of indicators (Bagozzi and Edwards 1998; Little et al. 2002). A parcel represents an aggregate-level indicator comprised of the average of two or more items. In line with the existing literature, we conceptualize e-service quality as a multidimensional construct of higher order (Brady and Cronin 2001; Fassnacht and Koese 2006). Therefore, we construct domain-representative parcels. This approach "accounts for multidimensionality by creating parcels that encompass not only the common variance (...), but also the reliable unique facets of multiple dimensions" (Little et al. 2002, p. 167). In particular, domain-representative parcels are created by joining and averaging items from different dimensions. The operationalization and validation of the domain-representative parcels will be described in more detail in the results section.

Nonlinear structural equation modeling

In line with Mittal et al. (1998) and Agustin and Singh (2005), asymmetry inherently implies nonlinearity in the functional relationship between service quality and satisfaction. That is, a negative asymmetry involves a function with diminishing returns to quality while a positive asymmetry involves increasing returns to quality. Literature suggests exploring decreasing or increasing returns to scale by introducing squared terms in the regression equations (Mittal et al. 1998). Given the advantages of structural equation modeling (SEM), we set out to test the hypothesized asymmetric effects by means of a nonlinear SEM approach including latent quadratic variables (Kenny and Judd 1984; Ping 1996). While several approaches have been suggested for testing structural equation models with latent quadratic terms (e.g., Ping 1996; Marsh et al. 2004), nonlinear effects are rarely implemented because of the inherent problems in the model specification and the technical complexity of analysis.

We apply the unconstrained approach proposed by Marsh et al. (2004) as it offers important advantages such as smaller bias and robustness regarding violations of multivariate normality assumptions. According to this approach, latent interaction terms are added to the base model. These terms are specified based on quadratics of the indicators for the latent variables in question. In contrast to the constrained approach, factor loadings and measurement error variances are allowed to be estimated freely rather than constrained (Jaiswal and Niraj 2007). In addition, all indicator variables as well as customer experience as the moderating variable are mean-centered to reduce multicollinearity and to augment informational value of significance tests (Algina and Moulder 2001). The square of the centered indicators is used to define the latent quadratic term. For example, if $\xi_{1}$ represents a latent construct and $x_{1}$ and $x_{2}$ are its indicators, then the terms $x_{1}^{2}$ and $x_{2}^{2}$ are specified as the indicators of the latent quadratic factor $\xi_{1}^{2}$. In particular, the indicator loading $\lambda_{x_{1}^{2}}$ and measurement error $\theta_{x_{1}^{2}}$ for the indicator $x_{1}$ of the quadratic factor are freely estimated in the following equations where $\delta_{x_{1}^{2}}$ represents the error term:

$x_{1}^{2}=\lambda_{x_{1}} \xi_{1}^{2}+\delta_{x_{1}^{2}}$

$\theta_{x_{1}^{2}}=\operatorname{var}\left(\delta_{x_{1}^{2}}\right)$

We model functional-utilitarian and hedonic e-service quality as reflective first-order constructs encompassing three domain-representative item parcels each. The respective quadratic factors are represented by building parcels of the mean-centered squared items (Little et al. 2002). Moreover, we include the interaction effect between functional and hedonic e-service quality. Not simultaneously considering the quadratic terms and the interaction of the underlying linear terms may entail misleading conclusions (Ganzach 1997). We constructed the described interaction effect by using the products of the first item parcels, second item parcels and third item parcels of the two e-service quality constructs as indicators of the latent interaction variable (Ping 1996).

Finally, customer experience is hypothesized to alter the nonlinear relationship between our independent variables and customer satisfaction. To model this effect, we introduce two nonredundant components in the structural equation model (Cohen et al. 2003, Luo and Donthu 2006): (1) a lower-order term representing the linear by linear interaction and (2) a higher-order term representing the nonlinear (quadratic) by linear interaction. ${ }^{3}$ The nonlinear by linear interaction can only be tested if all the other terms (including the linear by linear interactions) are integrated in the model represented by equation (3). To sum up, we use the following equation for testing the asymmetric effects of e-service quality on customer satisfaction

$$
\begin{aligned}
S A T= & \alpha+\beta_{1} F Q+\gamma_{1} F Q^{2}+\beta_{2} H Q \\
& +\gamma_{2} H Q^{2}+\gamma_{3} F Q^{*} E X P+\gamma_{4} F Q^{2 *} E X P \\
& +\gamma_{5} H Q^{*} E X P+\gamma_{6} H Q^{2 *} E X P+\gamma_{7} F Q^{*} H Q+\zeta
\end{aligned}
$$

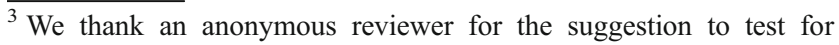
nonlinear by linear interaction effects.
} 
In equation (3), SAT represents customer satisfaction, $\alpha$ represents the constant term, $\beta_{\mathrm{i}}(\mathrm{i}=1,2)$ are the linear effects, $\gamma_{i}(i=1, \ldots, 7)$ are the quadratic and interaction effects respectively, $F Q$ reflects functional-utilitarian and $H Q$ represents hedonic e-service quality, $F Q^{2}$ and $H Q^{2}$ are the corresponding quadratic constructs, EXP represents customer experience and $\zeta$ indicates the error term.

\section{Results}

\section{Data pooling}

A general problem involved in applying nonlinear SEM is the nonnormal distribution of the quadratic term of an indicator even in the case of normally distributed raw data (Marsh et al. 2004). As a consequence, the distributional assumptions of maximum likelihood (ML) estimation are violated. This is especially the case for smaller to medium sample sizes increasing the likelihood of type II-errors when testing relationships between the constructs (SchermellehEngel et al. 1998). In order to minimize type II-errors, we tested for pooling the data obtained in both empirical settings (De Wulf et al. 2001). To decide whether we are able to pool data across service settings, we test for measurement invariance. In other words, we test whether the relation between indicators and latent variables is the same across both samples (Steenkamp and Baumgartner 1998). We apply multigroup analysis to compare the fit of two nested measurement models: (1) a free model in which item loadings are freely estimated across both samples, and (2) an equal model in which two item loadings per construct are set equal across the two samples. The models include all first-order constructs, i.e., the four functionalutilitarian quality constructs, the three hedonic quality constructs and customer satisfaction (Ping 2004). In assessing the differences in fit, the $\chi^{2}$-difference test is performed first. We find a significant $\chi^{2}$-deterioration $(p<.001)$ between the free model and the equal model $\left(\chi^{2}\right.$ free $(448)=1281.3$ and $\left.\chi_{\text {equal }}^{2}(464)=1321.6\right)$. However, no significant deterioration is found in alternative fit measures $\left(\mathrm{CFI}_{\text {free }}=.96, \mathrm{CFI}_{\text {equal }}=.96 ; \mathrm{TLI}_{\text {free }}=.95, \mathrm{TLI}_{\text {equal }}=.95\right.$; RMSEA $_{\text {free }}=.043, \mathrm{RMSEA}_{\text {equal }}=.043$ ). In view of this, we further evaluate the modification indices (MIs) of the constrained parameters, looking for MIs that are large and exceptional (Cheung and Rensvold 2002; Steenkamp and Baumgartner 1998). Based on an investigation of the indices of local misfit, the loadings of two items with the highest MIs are released. In particular, two items (FUL2 and FUL3) for assessing fulfillment are set free. This seems appropriate as these items were adapted to the specific online shopping and Internet portal context.
Compared to the free model, the resulting partial invariant model shows no significant or substantial deterioration in fit and partial metric invariance is therefore accepted $\left(\chi_{\text {partial }}^{2}(462)=1299.6 ; \mathrm{CFI}_{\text {partial }}=.96, \mathrm{TLI}_{\text {partial }}=.95\right.$, RMSEA $\left._{\text {partial }}=.043\right)$. Consequently, we decide to pool the data. Finally, and in line with Parasuraman et al. (2005), pooling of the data is also suitable from a conceptual perspective in order to produce results that can be generalized across a variety of electronic services.

\section{Second-order model}

To reassure multidimensionality of our e-service quality measure and the construction of domain-representative parcels, we follow the procedure conducted by Voss et al. (2003). They develop a two-dimensional scale for capturing functional-utilitarian and hedonic aspects of consumer attitudes. Accordingly, we first test whether the seven eservice quality dimensions are reflective of the two correlated higher-order constructs, namely functionalutilitarian and hedonic e-service quality. Calculating a second-order model lends support to our contention $\left(\chi^{2}(181)=930.7, \mathrm{CFI}=.96, \mathrm{TLI}=.95, \mathrm{RMSEA}=.064\right)$. The second-order factor loadings are significantly large and positive, ranging from .80 to $.92(p<.001)$ for functionalutilitarian quality and from .63 to $.84(p<.001)$ for hedonic quality. Furthermore, the correlation between the two eservice quality constructs is substantive and significant (standardized $\varphi=.65, p<.001$ ). Next, we carefully examine discriminant validity between the two second-order constructs by applying the Fornell and Larcker (1981) test. This test requires the average variance extracted (AVE) of each construct to exceed the squared correlation shared between the latent constructs. The AVE estimates are .91 for functional-utilitarian quality and .89 for hedonic quality both exceeding squared correlation between the constructs of .42. Finally, we compare two models where the correlation between functional-utilitarian and hedonic quality is freely estimated in the first, and constrained to unity in the second model (Anderson and Gerbing 1988). The $\chi^{2}$-difference test is significant $\left(\Delta \chi^{2}(1)=6.1, p<.05\right)$ and suggests that the correlation between both constructs significantly differs from 1 . In sum, functional-utilitarian and hedonic e-service quality are distinct and capture different information, but are tied to a common higherorder construct.

Validity and reliability of the domain-representative parcels

After having established e-service quality as a multidimensional higher-order construct, we are able to build the domainrepresentative parcels. The first parcel representing 
functional-utilitarian e-service quality consists of the averaged sum of the first items from each of the four dimensions (i.e., system availability, efficiency, fulfillment, and privacy). The second parcel includes the averaged sum of the second items from each of the four dimensions. Finally, the third parcel encompasses the averaged sum of the third items from each of the four dimensions. A similar logic was applied with respect to hedonic e-service quality. In this manner, each parcel reflects all of the dimensions inherent within the set of indicators. As a result, we obtain two factors captured by three item parcels each.

To test the validity and reliability of the parcel-based measures, we use confirmatory factor analyses. Following Homburg et al. (2008), item reliabilities and construct reliabilities are assessed based on a full measurement model. Overall, the results point to desirable psychometric properties of our measures. In particular, individual item reliabilities are well above the suggested minimum value of .50 (Anderson and Gerbing 1988). Additionally, the composite reliability values are also well above the suggested minimum value of .70 (Nunnally 1978). The AVE for each construct exceeds the threshold value of .50 (Baumgartner and Homburg 1996). Finally, overall fit measures display a good fit of the applied measurement models. The details of our analyses are reported in Table 2.

In line with Ping (2004), we regard the measurement of the quadratic latent constructs as reliable and valid as the underlying e-service quality constructs show high levels of reliability and validity themselves.

\section{Test of hypotheses}

We tested our hypotheses by estimating equation (3) with the unconstrained approach in a structural equation model using the maximum likelihood estimation procedure (Marsh et al. 2004). The fit statistics point to an acceptable fit of the structural model with the empirical data $\left(\chi^{2}(360)=1760.4\right.$, $\mathrm{CFI}=.94, \mathrm{TLI}=.93, \mathrm{RMSEA}=.062)$ and correspond to values reported in similar approaches (e.g., Agustin and Singh 2005). ${ }^{4}$ Overall, our model explains $72 \%$ of the variance in customer satisfaction.

To test our hypotheses, we interpret the path coefficients of the structural model, given the presence of all other terms in the equation (Cohen et al. 2003). As a first observation, $\beta_{1}$ and $\gamma_{1}$ are both significant and point to an

\footnotetext{
${ }^{4}$ The standardized first-order (second-order) factor loadings of the model constructs are all significant $(p<.001)$ and range from .93 to .96 (from .88 to .95 ) for functional-utilitarian e-service quality and from .91 to .95 (from .79 to .96 ) for hedonic e-service quality.
}

asymmetric effect of functional-utilitarian quality on satisfaction. As both path coefficients are positive $\left(\beta_{1}=.65\right.$, $p<.001$ and $\gamma_{1}=.15, p<.05$ ), the main effect (i.e., without considering customer experience interaction) for functionalutilitarian quality on satisfaction represents a positive asymmetry. Additionally, for hedonic e-service quality the linear parameter estimate is significant and positive $\left(\beta_{2}=.29, p<.001\right)$ while the quadratic parameter estimate is significant and negative $\left(\gamma_{2}=-.22, p<.01\right)$. Hence, the main effect of hedonic quality on satisfaction can be typified as negative asymmetric. Note that the inclusion of the interaction between both quality attributes assures the correct interpretation of our findings (Table 3).

Hypothesis 1 proposes decreasing returns to quality of functional-utilitarian website attributes as customer experience increases. Accordingly, the linear by linear interaction between quality and experience should be significantly positive while the nonlinear by linear interaction between the squared quality construct and experience is significantly negative (Cohen et al. 2003). We find exactly this pattern in our data $\left(\gamma_{3}=.20, p<.05\right.$; $\left.\gamma_{4}=-.22, p<.05\right)$. As the quadratic parameter estimate for functional-utilitarian quality is positive while the estimate for the interaction between the quadratic construct and experience is negative, the positive asymmetry shifts to a negative asymmetry with enhancing experience. Hence, hypothesis 1 is supported.

Hypothesis 2 posits increasing returns to quality of hedonic website features as customer experience increases. Thus, in order to support this hypothesis, the linear interaction between quality and experience as well as the nonlinear by linear interaction between the squared quality construct and experience have to be significantly positive (Cohen et al. 2003). Indeed, both interaction effects turn out to be significant and positive $\left(\gamma_{5}=.16, p<.05\right.$ and $\gamma_{6}=.15$, $p<.05$ ). For hedonic quality, the negative asymmetry converts into positive asymmetry for long-term customers as the quadratic parameter estimate is negative while the estimate for the interaction between the quadratic construct and experience is positive. That is, high levels of experience appear to overcome the decrease in satisfaction at high hedonic quality. Thus, hypothesis 2 is supported. Figure 1 depicts the results of our analyses.

\section{Conclusion}

This paper set out to provide deeper insight in the fundament of the satisfaction-profit chain by exploring the influence of service quality on satisfaction from an asymmetric and dynamic perspective. Building on customer delight theory and a hierarchy of needs framework, we 
Table 2 Measurement model results for the latent constructs

\begin{tabular}{|c|c|c|c|c|}
\hline $\begin{array}{l}\text { Construct } \\
\text { Item }\end{array}$ & Mean (SD) & Item reliability & Composite reliability & Average variance extracted \\
\hline Functional-utilitarian e-service quality & & & .97 & .91 \\
\hline FQ1 (SAV1+EFF1+FUL1+PRIV1) & $5.38(1.29)$ & .94 & & \\
\hline FQ2 (SAV2+EFF2+FUL2+PRIV2) & $5.36(1.29)$ & .92 & & \\
\hline FQ3 (SAV3+EFF3+FUL3+PRIV3) & $5.28(1.30)$ & .89 & & \\
\hline Hedonic e-service quality & & & .96 & .89 \\
\hline HQ1 (WEBDES1+ENJOY1+IMAG1) & $5.17(1.38)$ & .94 & & \\
\hline HQ2 (WEBDES2+ENJOY2+IMAG2) & $4.92(1.25)$ & .84 & & \\
\hline HQ3 (WEBDES3+ENJOY3+IMAG3) & $4.93(1.27)$ & .91 & & \\
\hline Customer satisfaction & & & .93 & .82 \\
\hline SAT1 & $5.30(1.60)$ & .83 & & \\
\hline SAT2 & $5.05(1.75)$ & .71 & & \\
\hline SAT3 & $5.26(1.56)$ & .77 & & \\
\hline
\end{tabular}

Overall fit measures: $\chi^{2}(24)=69.3, \mathrm{CFI}=.99, \mathrm{TLI}=.99, \mathrm{RMSEA}=.045$

See appendix for item wordings matching the abbreviations.

developed two hypotheses in order to compare the role of functional-utilitarian and hedonic quality in affecting satisfaction for customers varying in experience with an e-service. As an important first insight, our study shows that the nature of the quality-satisfaction link is nonlinear and asymmetric. Testing our hypotheses using a nonlinear SEM approach including latent quadratic terms, we detect positive asymmetric main effects of functional-utilitarian website features on customer satisfaction. In contrast, hedonic quality characteristics exhibit negative asymmetric effects on customer satisfaction. These results extend previous findings in offline and online contexts. For instance, Mittal et al. (1998) demonstrate only negative asymmetric effects of attribute performance on customer

Table 3 Relationships between e-service quality and customer satisfaction

\begin{tabular}{|c|c|c|c|c|}
\hline \multirow[t]{2}{*}{ Independent variable } & \multicolumn{3}{|c|}{ Dependent variable: customer satisfaction } & \multirow[b]{2}{*}{$\begin{array}{l}\text { Hypotheses } \\
\text { test }\end{array}$} \\
\hline & Coefficient $^{\mathrm{a}}$ & t-value & Conclusion & \\
\hline Functional-utilitarian e-service quality & .65 & $8.55^{* * *}$ & & \\
\hline Functional-utilitarian e-service quality ${ }^{2}$ & .15 & $2.23 *$ & Positive asymmetric effect & \\
\hline Functional-utilitarian e-service quality $\mathrm{x}$ experience & .20 & $2.04 *$ & & \\
\hline Functional-utilitarian e-service quality ${ }^{2} \mathrm{x}$ experience & -.22 & $-2.16^{*}$ & $\begin{array}{l}\text { Negative asymmetric effect as } \\
\text { customer experience increases }\end{array}$ & H1 supported \\
\hline Hedonic e-service quality & .29 & $4.22 * * *$ & & \\
\hline Hedonic e-service quality ${ }^{2}$ & -.22 & $-2.96^{* *}$ & Negative asymmetric effect & \\
\hline Hedonic e-service quality $\mathrm{x}$ experience & .16 & $1.99 *$ & & \\
\hline Hedonic e-service quality ${ }^{2} \mathrm{x}$ experience & .15 & $1.96^{*}$ & $\begin{array}{l}\text { Positive asymmetric effect as } \\
\text { customer experience increases }\end{array}$ & H2 supported \\
\hline Functional-utilitarian $\mathrm{x}$ hedonic e-service quality & .09 & $1.51^{\text {n.s. }}$ & $\begin{array}{l}\text { Meaningful interpretation of the } \\
\text { quadratic terms assured }\end{array}$ & \\
\hline
\end{tabular}

Overall fit measures: $\chi^{2}(360)=1760.4, \mathrm{CFI}=.94, \mathrm{TLI}=.93, \mathrm{RMSEA}=.062$

${ }^{*} p<.05, * * p<.01, * * * p<.001$, n.s. $=$ not significant

${ }^{a}$ Standardized estimates 


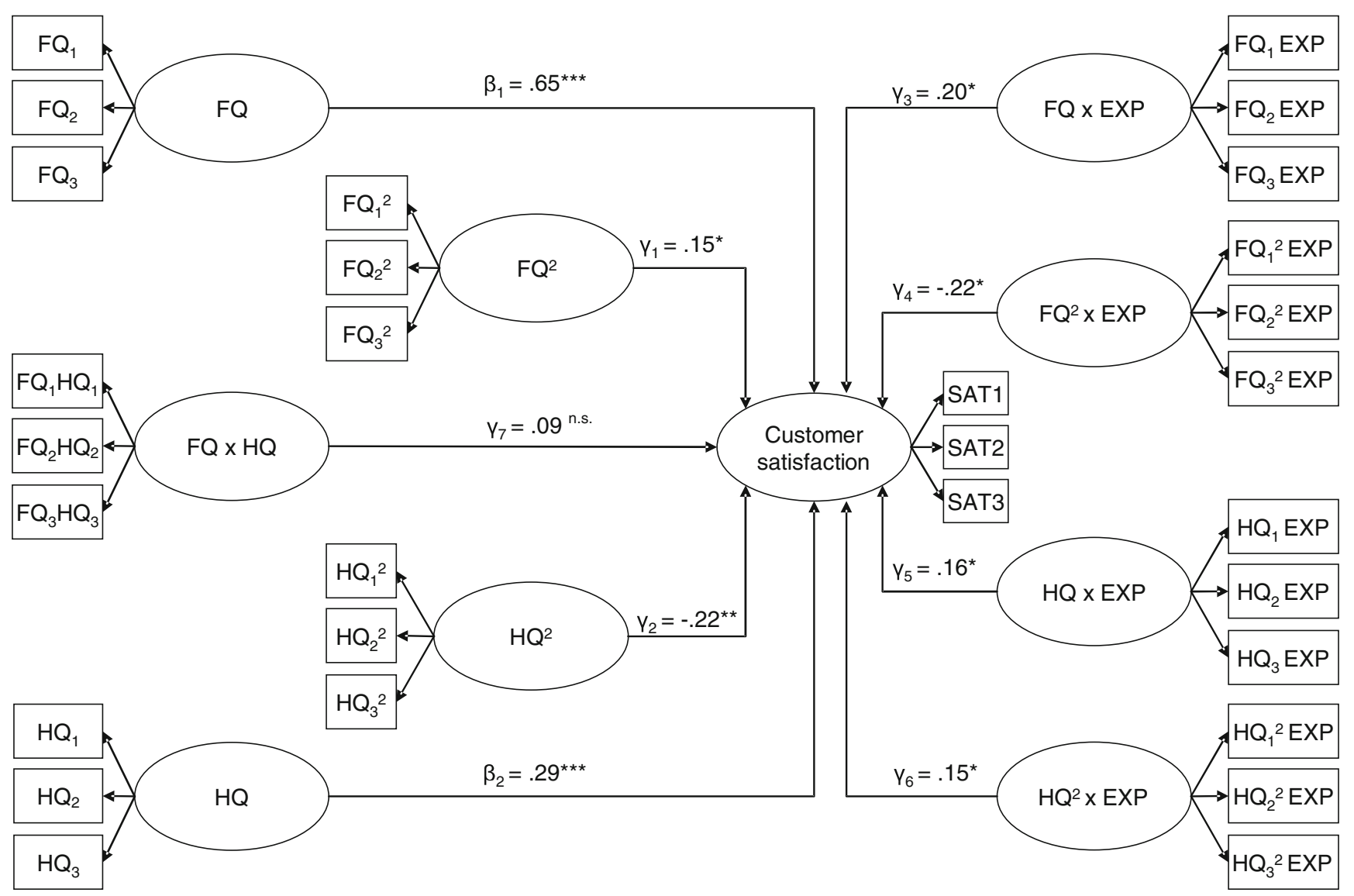

Figure 1 Asymmetric and dynamic effects of e-service quality on customer satisfaction.

$* p<.05, * * p<.01, * * * p<.001$, n.s. $=$ not significant.

Notes: $\mathrm{FQ}=$ functional-utilitarian quality, $\mathrm{HQ}=$ hedonic quality, $\mathrm{FQ} \times$ $\mathrm{HQ}=$ functional-utilitarian - hedonic quality interaction, $\mathrm{FQ}^{2}=$ functional-

satisfaction with medical services. Cheung and Lee (2005) find both negative and positive asymmetric effect of web site attribute performance on satisfaction, but do not consider hedonic attributes.

Second, the identified asymmetries in the qualitysatisfaction link shift over time. Regarding the initial positive asymmetry for functional-utilitarian attributes, we witness a significant decline in their potential to spark high levels of satisfaction as customer experience increases. Figure 2, Panel A plots the described relationship between functional-utilitarian quality, customer experience and satisfaction. Interpreting the plot in Fig. 2, Panel A, satisfaction returns to functional-utilitarian quality rise with increasing experience to a point. Then, with higher experience, the impact of functional quality on customer satisfaction is incrementally lowered. Put differently, for customers low in experience, we observe increasing returns for functional quality, while this relationship turns into one with decreasing returns to scale for experienced customers. utilitarian quality quadratic term, $\mathrm{HQ}^{2}=$ hedonic quality quadratic term, $\mathrm{FQ} \times \mathrm{EXP}=$ functional-utilitarian quality - experience interaction, $\mathrm{HQ} \times$ $\mathrm{EXP}=$ hedonic quality - experience interaction, $\mathrm{FQ}^{2} \mathrm{x} \mathrm{EXP}=$ functionalutilitarian quality quadratic - experience interaction, and $\mathrm{HQ}^{2} \mathrm{x}$ $\mathrm{EXP}=$ hedonic quality quadratic - experience interaction.

Therefore, the graph of the satisfaction function is S-shaped with a turning point at which the asymmetry changes valence from positive to negative.

Consequently, for inexperienced customers, service provision should be convenient, accurate, and reliable. For instance, providers should offer well-structured content and high ease of use. Additionally, the quality of firewalls, the provision of privacy policies, and the explicitness of security measures should receive ample attention to overcome the "zone-of-intolerance" which precludes customers from engaging in a relationship with the service provider. Nevertheless, for experienced users, functional-utilitarian aspects of e-service quality show a negative asymmetric influence on satisfaction. Obviously, by engaging in an enduring relationship with the service provider, their fundamental needs have been satisfied and their focus has shifted to evaluating higher-order hedonic factors. A service provider investing in attributes creating structural firmness or functional convenience does not gain higher satisfaction 

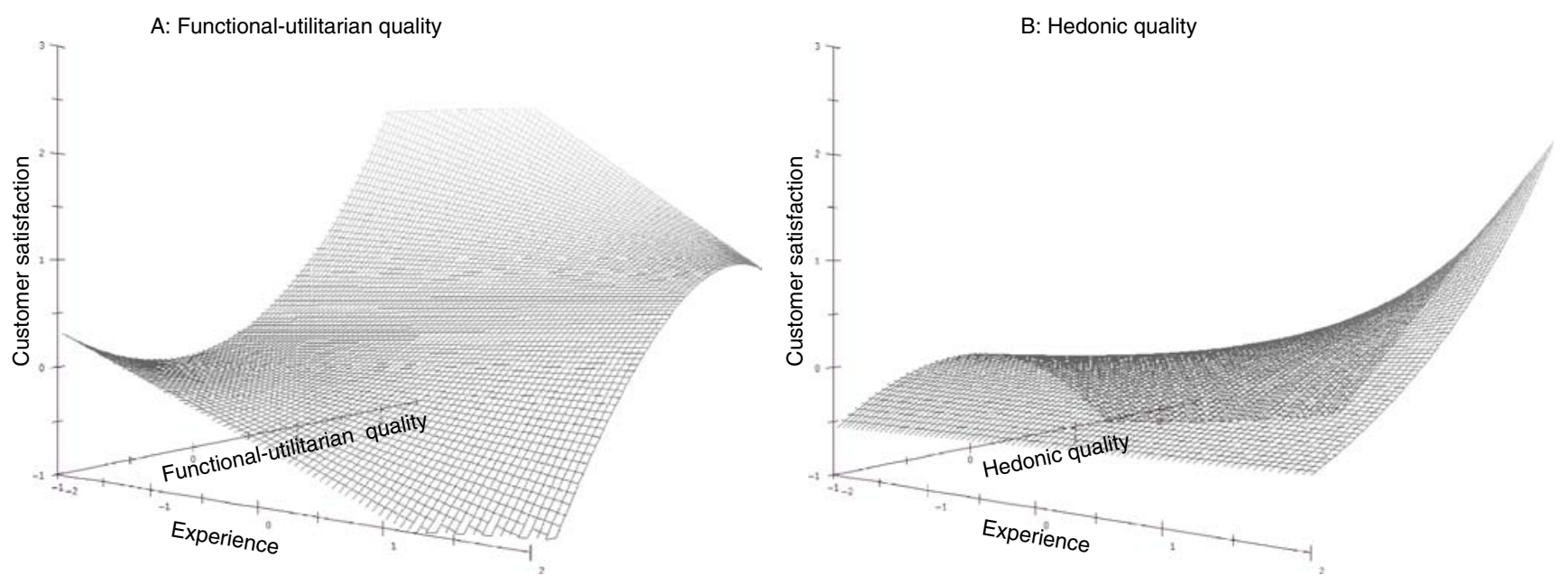

Figure 2 Asymmetric and dynamic effects of e-service quality on customer satisfaction.

Note: The three-dimensional graphs are partial plots over the observed domain of the two independent variables included.

scores over the course of time. However, performing below market standard on aspects like clear navigation menus, on-time delivery, reliable page availability or Secure Socket Layer (SSL) data protection is a critical flaw. To sum up, exceeding functional-utilitarian quality expectations does not pay off, while underperforming may be dangerous.

Third, our results provide striking evidence for a time-dependent shift in the dominance of delight creating factors from functional to hedonic attributes. We find hedonic e-service quality attributes to exhibit an upward pattern from negative to positive asymmetries. The plot in Fig. 2, Panel B illustrates simultaneous effects of hedonic quality and experience on customer satisfaction. Interpreting the plot, the satisfaction function forms an inverted S-shaped surface. With growing customer experience, the initially decreasing returns to hedonic quality shift to increasing returns after having reached a turning point. As a consequence, higher-order hedonic needs gain importance for experienced customers and the corresponding quality attributes only then acquire the potential to spark delight. The potential of hedonic elements to delight only more experienced customers corresponds to insights in the recent trend of service providers developing online customer communities. Community users carry pride in being recognized as users of an Internet portal (Mathwick et al. 2008), but getting social support and building social capital only works out for longterm users. Customers need to be long-standing and active users of the community in order to build their expert image vis-à-vis other customers and leverage their (online) social network.
In sum, customers tend to start with online shopping as an alternative channel to offline shopping. However, as customers get familiar with all functionalities, they open themselves for the fun mode of shopping. More specifically, inexperienced customers gain little satisfaction from customizable layouts, large community networks and fun experiences such as trivia's, games and chat functions. In fact, these elements have the ability to boost satisfaction for the more experienced e-service consumer. This contrasts suggestions based on flow theory stating that enjoyment is a general precondition for using the Internet and that the Internet is basically an "entertainment medium" (Orwall 2001).

\section{Managerial implications}

Our results emphasize the necessity of considering both functional-utilitarian and hedonic quality attributes throughout the e-service provision. Moreover, they contradict the erroneous beliefs of many service managers sticking to the linear quality-satisfaction relationship paradigm. The tenacity of belief in this paradigm is a possible explanation for the frustration of many e-service providers with the outcomes of their quality management. Some of them have even called for abandoning service quality management as a means for enhancing satisfaction (Anderson and Mittal 2000). Instead, if asymmetries are taken into account, overspending for "negative" and underspending for "positive" attributes can be avoided. Thus, our approach helps e-service managers to coexist with finance and operations by mapping service-related expenditures. 
Functional aspects of using e-services can trigger delight for inexperienced customers and should at least be up-tostandard when targeting new customers. While "newbies" are easily impressed by features like well arranged content, order fulfillment, low downtimes and state-of-the-art data protection, the delight-creating potential of functionalutilitarian attributes continuously decreases over time. These structural elements of a website comprise the most basic needs of online consumers (Valacich et al. 2007). As hedonic attributes acquire a customer focus only later, this calls for dynamically personalizing a website. In "personalization 2.0", the information provided by the customer, together with his/her purchase history and privacy settings form a customer scenario, which a website can use to match a customer to marketing activity (Needles 2008). For instance, portal users often log in first for checking their email. Usage information is consequently registered in the user's profile, which could include visit frequency, clickstream behavior, or transactions (Winer 2009).

Regarding the content of customization, inexperienced customers should be exposed to features like easy access website policies, product information, quick links or guided tours by means of avatars (i.e., virtual characters). After a learning period and gaining experience with the e-service, more hedonic elements may be added to generate emotional responses. Possibilities include chat functions with other customers, customizable website look and feel, displaying products in a 3D virtual walk-through shop instead of scrollable listings, or lotteries for free products. However, it has to be noted that firms should not lose sight of functional-utilitarian attributes when improving the hedonic elements as advancing technical features as well might be necessary as a response to competitors' moves. In other words, if a competitor raises the bar of performance, this might well grow to be a market standard (File et al. 1994). Performing under the market standard on a negative asymmetric attribute will be met with a large amount of customer dissatisfaction. In addition, exposing a customer to new and improved features on a too regular basis may cause feature fatigue.
Thompson et al. (2005) show that mental exhaustion and stress can be caused by products that come with a too large number of features.

Limitations and future research directions

Our study opens several interesting avenues for future research. First, this study is among the first to statistically test asymmetries in the relationship between service quality and customer satisfaction by means of a nonlinear structural equation modeling approach. However, while we chose robustness over detail when specifying our structural model using second-order constructs, future studies could make a contribution by assessing asymmetries on first-order level. Second, where we focus on the relationship between service quality and customer satisfaction, Anderson and Mittal (2000) suggest that more relationships in the satisfaction-profit chain may be nonlinear. Consequently, future studies could statistically substantiate the asymmetric nature of the customer satisfaction-customer profitability link. A service provider's capability of converting satisfaction assets into profitable outputs is an aspect gaining increased importance (Gupta and Zeithaml 2006). By examining a causeand-effect chain leading from service quality investments via satisfaction to customer profitability, the total effect of service quality initiatives on a firm's financial performance can be traced. Third, with respect to the survey method, a self selection bias might exist. However, empirical results show that this bias is weaker than typically proposed in the literature. Deutskens et al. (2006) found that in many cases generalizability bias is negligible. Fourth, acquiescence is one but not the only source of common method bias. Therefore, future studies could explicitly incorporate a common method factor along with an acquiescence factor in their models (Agustin and Singh 2005). Finally, while using a customer experience variable is a statistically sound method for drafting dynamic effects, future studies could monitor each specific customer over the course of time by applying a longitudinal design. 
Appendix Scale items for construct measures

\begin{tabular}{|c|c|c|c|c|}
\hline Construct & Item & $\begin{array}{l}\text { Item } \\
\text { reliability }\end{array}$ & $\begin{array}{l}\text { Composite } \\
\text { reliability }\end{array}$ & $\begin{array}{l}\text { Average } \\
\text { variance } \\
\text { extracted }\end{array}$ \\
\hline \multirow{3}{*}{$\begin{array}{l}\text { System } \\
\text { availability }\end{array}$} & This website is always available for business. (SAV1) & .81 & \multirow[t]{3}{*}{.91} & \multirow[t]{3}{*}{.78} \\
\hline & This website launches and runs right away. (SAV2) & .81 & & \\
\hline & This website does not crash. (SAV3) & .72 & & \\
\hline \multirow[t]{3}{*}{ Efficiency } & This website makes it easy to get anywhere on the site. (EFF1) & .64 & \multirow[t]{3}{*}{.89} & \multirow[t]{3}{*}{.73} \\
\hline & This website loads its pages fast. (EFF2) & .79 & & \\
\hline & This website is simple to use. (EFF3) & .76 & & \\
\hline \multirow[t]{6}{*}{ Fulfillment } & This website delivers orders when promised. (FUL1 Shop) & .77 & \multirow[t]{6}{*}{.89} & \multirow[t]{6}{*}{.72} \\
\hline & This website gives accurate price and product comparisons as promised. (FUL1 Portal) & & & \\
\hline & This website sends out the items ordered. (FUL2 Shop) & .72 & & \\
\hline & This website delivers relevant price and product comparisons. (FUL2 Portal) & & & \\
\hline & This website makes accurate promises about delivery of products. (FUL3 Shop) & 67 & & \\
\hline & This website makes accurate promises about price and product comparisons. (FUL3 Portal) & & & \\
\hline \multirow[t]{3}{*}{ Privacy } & This website protects information about my web-shopping behavior. (PRIV1) & .79 & \multirow[t]{3}{*}{.89} & \multirow[t]{3}{*}{.73} \\
\hline & This website does not share my personal information with other sites. (PRIV2) & .76 & & \\
\hline & I can trust this website. (PRIV3) & .62 & & \\
\hline \multirow[t]{3}{*}{ Website design } & This website is visually appealing. (WEBDES1) & .76 & \multirow[t]{3}{*}{.85} & \multirow[t]{3}{*}{.66} \\
\hline & This website's appearance is professional. (WEBDES2) & .74 & & \\
\hline & This website has innovative features. (WEBDES3) & .48 & & \\
\hline \multirow[t]{3}{*}{ Enjoyment } & Shopping at this website is exciting. (ENJOY1) & .85 & \multirow[t]{3}{*}{.92} & \multirow[t]{3}{*}{.80} \\
\hline & Shopping at this website is interesting. (ENJOY2) & .85 & & \\
\hline & Shopping at this website is enjoyable. (ENJOY3) & .71 & & \\
\hline \multirow[t]{3}{*}{ Image } & $\begin{array}{l}\text { People in my personal environment who use this website have more prestige than those } \\
\text { who do not. (IMAG1) }\end{array}$ & .87 & \multirow[t]{3}{*}{.95} & \multirow[t]{3}{*}{.86} \\
\hline & People in my personal environment who use this website have a high profile. (IMAG2) & .87 & & \\
\hline & Using this website is a status symbol in my personal environment. (IMAG3) & .86 & & \\
\hline \multirow{4}{*}{$\begin{array}{l}\text { Customer } \\
\text { satisfaction }\end{array}$} & Overall, how do you feel about your experience with the online shop? & & \multirow[t]{4}{*}{.93} & \multirow[t]{4}{*}{.83} \\
\hline & Very dissatisfied $(=1)$ to very satisfied $(=7)(\mathrm{SAT} 1)$ & .90 & & \\
\hline & Very displeased $(=1)$ to very pleased $(=7)(\mathrm{SAT} 2)$ & .73 & & \\
\hline & I think I did the right thing when I decided to use this online shop. (SAT3) & .84 & & \\
\hline
\end{tabular}

Note: Results are based on a full confirmatory factor analysis containing functional-utilitarian and hedonic quality as second-order constructs and customer satisfaction as a first-order construct.

Acknowledgement The authors would like to thank the editor and four anonymous reviewers for their valuable comments on earlier drafts of the manuscript.

Open Access This article is distributed under the terms of the Creative Commons Attribution Noncommercial License which permits any noncommercial use, distribution, and reproduction in any medium, provided the original author(s) and source are credited.

\section{References}

Agustin, C., \& Singh, J. (2005). Curvilinear effects of consumer loyalty determinants in relational exchanges. JMR, Journal of
Marketing Research, 42(1), 96-108. doi:10.1509/jmkr.42.1.96. 56961.

Algina, J., \& Moulder, B. C. (2001). A note on estimating the Jöreskog-Yang model for latent variable interaction using LISREL 8.3. Structural Equation Modeling, 8(1), 40-52. doi:10.1207/S15328007SEM0801 3.

Anderson, E. W. (2006). Linking service and finance. Marketing Science, 25(6), 587-589. doi:10.1287/mksc.1050.0172.

Anderson, J. C., \& Gerbing, D. W. (1988). Structural equation modeling in practice: a review and recommended two-step approach. Psychological Bulletin, 103(3), 411-423. doi:10.1037/0033-2909. 103.3.411.

Anderson, E. W., \& Mittal, V. (2000). Strengthening the satisfactionprofit chain. Journal of Service Research, 3(2), 107-120. doi:10.1177/109467050032001. 
Anderson, S. W., Pearo, L. K., \& Widener, S. K. (2008). Drivers of service satisfaction: linking customer satisfaction to the service concept and customer characteristics. Journal of Service Research, 10(4), 365-381.

Bagozzi, R. P., \& Edwards, J. R. (1998). A general approach for representing constructs in organizational research. Organizational Research Methods, 1(1), 45-87. doi:10.1177/109442819800100104.

Bauer, H. H., Falk, T., \& Hammerschmidt, M. (2006). eTransQual. A transaction process-based approach for capturing service quality in online shopping. Journal of Business Research, 59(7), 866875. doi:10.1016/j.jbusres.2006.01.021.

Baumgartner, H., \& Homburg, C. (1996). Applications of structural equation modeling in marketing and consumer research: a review. International Journal of Research in Marketing, 13(2), 139-161. doi:10.1016/0167-8116(95)00038-0.

Bolton, R. N., \& Lemon, K. N. (1999). A dynamic model of customers' usage of services: usage as an antecedent and consequence of satisfaction. JMR, Journal of Marketing Research, 36(2), 171-186. doi:10.2307/3152091.

Brady, M. K., \& Cronin, J. J. (2001). Some new thoughts on conceptualizing perceived service quality: a hierarchical approach. Journal of Marketing, 65(3), 34-49. doi:10.1509/ jmkg.65.3.34.18334.

Cheung, C. M. K., \& Lee, M. K. O. (2005). The asymmetric effect of web site attribute performance on web satisfaction: an empirical study. e-Service Journal, 3(3), 65-86.

Cheung, G. W., \& Rensvold, R. B. (2002). Evaluating goodness-of-fit indexes for testing measurement invariance. Structural Equation Modeling, 9(2), 233-255. doi:10.1207/S15328007SEM0902 5.

Childers, T. L., Carr, C. L., Peck, J., \& Carson, S. (2001). Hedonic and utilitarian motivations for online retail shopping behavior. Journal of Retailing, 77(4), 511-535. doi:10.1016/S0022-4359 (01)00056-2.

Chitturi, R., Raghunathan, R., \& Mahajan, V. (2008). Delight by design: the role of hedonic versus utilitarian benefits. Journal of Marketing, 72(3), 48-63. doi:10.1509/jmkg.72.3.48.

Cohen, J., Cohen, P., West, S. G., \& Aiken, L. S. (2003). Applied multiple regression/correlation analysis for the behavioral sciences. $3^{\text {rd }}$ ed. Mahwah: Lawrence Erlbaum Associates.

Dagger, T. S., \& Sweeney, J. C. (2007). Service quality attribute weights. Journal of Service Research, 10(1), 22-42. doi:10.1177/ 1094670507303010

Deutskens, E., de Jong, A., de Ruyter, K., \& Wetzels, M. (2006). Comparing the generalizability of online and mail surveys in cross-national service quality research. Marketing Letters, 17(2), 119-136. doi:10.1007/s11002-006-4950-8.

De Wulf, K., Odekerken-Schröder, G., \& Iacobucci, D. (2001). Investments in Consumer Relationships: A Cross-Country and Cross-Industry Exploration. Journal of Marketing, 65(4), 33-50.

Dhar, R., \& Wertenbroch, K. (2000). Consumer choice between hedonic and utilitarian goods. JMR, Journal of Marketing Research, 37(1), 60-71. doi:10.1509/jmkr.37.1.60.18718.

Fassnacht, M., \& Koese, I. (2006). Quality of electronic services. Journal of Service Research, 9(1), 19-37. doi:10.1177/1094670506289531.

File, K. M., Cermak, D. S. P., \& Prince, R. A. (1994). Word-of-mouth effects in professional services buyer behaviour. Service Industries Journal, 14(3), 301-314. doi:10.1080/02642069400000035.

Fornell, C., \& Larcker, D. F. (1981). Evaluating structural equation models with unobservable variables and measurement error. JMR, Journal of Marketing Research, 18(1), 39-50. doi:10.2307/3151312.

Ganzach, Y. (1997). Misleading interaction and curvilinear terms. Psychological Methods, 2(3), 235-247. doi:10.1037/1082989X.2.3.235.

Gupta, S., \& Zeithaml, V. A. (2006). Customer metrics and their impact on financial performance. Marketing Science, 25(6), 718739. doi:10.1287/mksc.1060.0221.
Hennig-Thurau, T., Gwinner, K. P., \& Gremler, D. D. (2002). Understanding relationship marketing outcomes: an integration of relational benefits and relationship quality. Journal of Service Research, 4(3), 230-247. doi:10.1177/1094670502004003006.

Homburg, C., Koschate, N., \& Hoyer, W. D. (2005). The role of cognition and affect in the formation of customer satisfaction: a dynamic perspective. Journal of Marketing, 70(3), 21-31. doi: $10.1509 /$ jmkg.70.3.21.

Homburg, C., Droll, M., \& Totzek, D. (2008). Customer prioritization: does it pay off, and how should it be implemented? Journal of Marketing, 72(5), 110-130. doi:10.1509/jmkg.72.5.110.

Jaiswal, A. K., \& Niraj, R. (2007). Examining the Nonlinear Effects in Satisfaction-Loyalty-Behavioral Intentions Models. Working Paper. Indian Institute of Management, Ahmedabad.

Johnson, M. D., Herrmann, A., \& Huber, F. (2006). The evolution of loyalty intentions. Journal of Marketing, 70(2), 122-132.

Kahneman, D., \& Tversky, A. (1979). Prospect theory: an analysis of decisions under risk. Econometrica, 47(2), 263-291. doi:10.2307/ 1914185.

Kano, N., Seraku, N., Takahashi, F., \& Tsuji, S. (1984). Attractive quality and must-be quality. Hinshitsu. The Journal of the Japanese Society for Quality Control, 14(2), 39-48.

Kenny, D. A., \& Judd, C. M. (1984). Estimating the nonlinear and interactive effects of latent variables. Psychological Bulletin, 96 (1), 201-210. doi:10.1037/0033-2909.96.1.201.

Little, T. D., Cunningham, W. A., Shahar, G., \& Widaman, K. F. (2002). To parcel or not to parcel: exploring the question, weighing the merits. Structural Equation Modeling, 9(2), 151173. doi:10.1207/S15328007SEM0902_1.

Luo, X., \& Donthu, N. (2006). Marketing credibility: a longitudinal investigation of marketing communication productivity and shareholder value. Journal of Marketing, 70(4), 70-91. doi:10.1509/jmkg.70.4.70.

Marsh, H. W., Wen, Z., \& Hau, K.-T. (2004). Structural equation models of latent interactions: evaluation of alternative estimation strategies and indicator construction. Psychological Methods, 9 (3), 275-300. doi:10.1037/1082-989X.9.3.275.

Maslow, A. (1954). Motivation and personality. New York: Harper \& Row.

Mathwick, C., Wiertz, C., \& de Ruyter, K. (2008). Social capital production in a virtual P3 community. The Journal of Consumer Research, 34(6), 832-849. doi:10.1086/523291.

Matzler, K., Bailom, F., Hinterhuber, H. H., Renzl, B., \& Pichler, J. (2004). The asymmetric relationship between attribute-level performance and overall customer satisfaction: a reconsideration of the importance-performance analysis. Industrial Marketing Management, 33(4), 271-278.

Mittal, V., \& Katrichis, J. M. (2000). Distinctions between new and loyal customers. Marketing Research, 12(1), 26-33.

Mittal, V., Ross, W. T., \& Baldasare, P. M. (1998). The asymmetric impact of negative and positive attribute-level performance on overall satisfaction and repurchase intention. Journal of Marketing, 62(1), 33-47. doi:10.2307/1251801.

Mittal, V., Kumar, P., \& Tsiros, M. (1999). Attribute-level performance, satisfaction and behavorial intentions over time: a consumption-system approach. Journal of Marketing, 63(2), 88-101. doi:10.2307/1251947.

Mittal, V., Katrichis, J. M., \& Kumar, P. (2001). Attribute performance and customer satisfaction over time: evidence from two field studies. Journal of Services Marketing, 15(4/5), 343-356. doi:10.1108/EUM0000000005655.

Needles, A. (2008). Marketing Personalization 2.0. Online Paper. Retrieved from http://propelling brands.wordpress.com/2008/11/ 06/marketing-personalization-20/ (last accessed 5-2-2008).

Nilsson-Witell, L., \& Fundin, A. (2005). Dynamics of service attributes: a test of Kano's theory of attractive quality. Interna- 
tional Journal of Service Industry Management, 16(2), 152-168. doi:10.1108/09564230510592289.

Nunnally, J. C. (1978). Psychometric theory. New York: McGrawHill.

Okada, E. M. (2005). Justification effects on consumer choice of hedonic and utilitarian goods. JMR, Journal of Marketing Research, 42(1), 43-53. doi:10.1509/jmkr.42.1.43.56889.

Oliver, R. L., Rust, R. T., \& Varki, S. (1997). Customer delight: foundations, findings, and managerial insight. Journal of Retailing, 73(3), 311-336. doi:10.1016/S0022-4359(97)90021-X.

Orwall, B. 2001. Thumbs up: What makes a good entertainment site click? Wall Street Journal March, 26, R 6.

Parasuraman, A., Berry, L. L., \& Zeithaml, V. A. (1991). Understanding customer expectations of service. Sloan Management Review, 32(3), 39-48

Parasuraman, A., Zeithaml, V. A., \& Malhotra, A. (2005). E-S-QUAL a multiple-item scale for assessing electronic service quality. Journal of Service Research, 7(3), 213-233. doi:10.1177/ 1094670504271156

Ping, R. A. (1996). Latent variable interaction and quadratic effect estimation: a two-step technique using structural equation analysis. Psychological Bulletin, 119(1), 166-175. doi:10.1037/ 0033-2909.119.1.166.

Ping, R. A. (2004). Testing latent variable models with survey data. Online Paper. Retrieved from http:/home.att.net/ rpingjr/lv1/toc1.htm.

Rust, R. T., \& Kannan, P. K. (2002). e-Service: new directions in theory and practice. New York: M.E. Sharpe.

Rust, R. T., \& Chung, T. S. (2006). Marketing Models of Service and Relationships. Marketing Science, 25(6), 560-580. doi:10.1287/ mksc. 1050.0139.

Rust, R. T., \& Oliver, R. L. (2000). Should we delight the customer? Journal of the Academy of Marketing Science, 28(1), 86-94. doi:10.1177/0092070300281008.

Rust, R. T., Inman, J., Jia, J., \& Zahorik, A. (1999). What you don't know about customer-perceived quality: the role of customer expectation distributions. Marketing Science, 18(1), 77-92. doi:10.1287/mksc.18.1.77.

Schermelleh-Engel, K., Klein, A., \& Moosbrugger, H. (1998). Estimating nonlinear effects using a latent moderated structural equations approach. In R. E. Schumacker \& G. A. Marcoulides (Eds.), Interaction and nonlinear effects in structural equation modeling. Mahwah: Lawrence Erlbaum Associates.

Slotegraaf, R. J., \& Inman, J. (2004). Longitudinal shifts in the drivers of satisfaction with product quality: the role of attribute resolvability. JMR, Journal of Marketing Research, 41(3), 269280. doi:10.1509/jmkr.41.3.269.35989.

Steenkamp, J.-B. E. M., \& Baumgartner, H. (1998). Assessing measurement invariance in cross-national consumer research. The Journal of Consumer Research, 25(1), 78-90. doi:10.1086/209528.

Szymanski, D. M., \& Hise, R. T. (2000). e-Satisfaction: an initial examination. Journal of Retailing, 76(3), 309-322. doi:10.1016/ S0022-4359(00)00035-X.

Thompson, D. V., Hamilton, R. W., \& Rust, R. T. (2005). Feature fatigue: when product capabilities become too much of a good thing. JMR, Journal of Marketing Research, 42(4), 431-442. doi:10.1509/jmkr.2005.42.4.431.

Valacich, J. S., Parboteeah, D. V., \& Wells, J. D. (2007). The online consumer's hierarchy of needs. Communications of the ACM, 50 (9), 84-90. doi:10.1145/1284621.1284624.

Van Dolen, W. M., Dabholkar, P. A., \& de Ruyter, K. (2007). Satisfaction with Online Commercial Group Chat: The Influence of Perceived Technology Attributes, Chat Group Characteristics, and Advisor Communication Style. Journal of Retailing, 83(3), 339-358.

Venkatesh, V., \& Davis, F. D. (2000). A theoretical extension of the technology acceptance model: four longitudinal field studies. Management Science, 46(2), 186-204. doi:10.1287/mnsc.46. 2.186.11926

Venkatesh, V., Morris, M. G., Davis, G. B., \& Davis, F. D. (2003). User acceptance of information technology: toward a unified view. MIS Quarterly, 27(3), 425-478.

Voss, K. E., Spangenberg, E. R., \& Grohman, B. (2003). Measuring the hedonic and utilitarian dimensions of consumer attitude. JMR, Journal of Marketing Research, 40(3), 310-320. doi:10.1509/jmkr.40.3.310.19238.

Weijters, B., Schillewaert, N., \& Geuens, M. (2008). Assessing response styles across modes of data collection. Journal of the Academy of Marketing Science, 36(3), 409-422. doi:10.1007/ s11747-007-0077-6.

Winer, R. S. (2009). New communication approaches in marketing: issues and research directions. Journal of Interactive Marketing, 23(2), 108-117.

Wolfinbarger, M., \& Gilly, M. C. (2003). eTailQ: dimensionalizing, measuring and predicting etail quality. Journal of Retailing, 79 (3), 183-198. doi:10.1016/S0022-4359(03)00034-4.

Zhang, P., \& von Dran, G. (2001). User expectations and rankings of quality factors in different web site domains. International Journal of Electronic Commerce, 6(2), 9-33. 